\title{
Influence of Tethers Tension Force on the response of Triangular Tension Leg Platform subjected to hydrodynamic waves
}

\author{
Amr R. El-gamal, Ashraf Essa, Ayman Ismail
}

\begin{abstract}
- compliant structures like triangular tension leg platforms (TLPs) are proven to be highly cost effective in deep waters. The estimation of hydraulic forces due to waves on structural member of TLP is vital for its economic and safe design. In the current study, a numerical study for a triangular TLP using modified Morison equation was carried out in the time domain with water particle kinematics using Airy's linear wave theory to investigate the effect of changing the tether tension force on the stiffness matrix of TLP's, the dynamic behavior of TLP's; and on the fatigue stresses in the cables. The effect was investigated for different parameters of the hydrodynamic forces such as wave periods, and wave heights. The numerical study takes into consideration the effect of coupling between various degrees of freedom. The stiffness of the TLP was derived from a combination of hydrostatic restoring forces and restoring forces due to cables. Nonlinear equation was solved using Newmark's beta integration method. Only uni-directional waves in the surge direction was considered in the analysis.
\end{abstract}

Keywords-Tethers tension, triangular tension leg platforms, hydrodynamic wave forces, wave characteristic.

\section{INTRODUCTION}

$\mathrm{D}$ rilling of oil wells in deeper sea is continuing with striking advances, reaching a water depth of more than $1000 \mathrm{~m}$. These water depths are associated with larger hydrodynamic effects and total base moment, finally resulting in more material. Offshore platforms are usually divided into two general categories, fixed and compliant. Fixed types extend to the seabed and remain in place by their weight or by piles driven into the soil. Compliant-type platforms are more responsive to external effects and their movements are controlled by mooring systems. The increase in cost of fixed offshore structures with depth of water encouraged the development of compliant- type structures. The key idea behind their installation is the minimization of the resistance of the structure to environmental loads by making the structure flexible. The

A. R. is with the Civil Engineering Department, Faculty of Engineering at Benha, Benha University, Assistant Lecturer, Egypt (phone: 00201000941720; fax: 13512; e-mail: engamrramadan@yahoo.com).

A. E. is with the Civil Engineering Department, National Building Research Center, Associated prof., Egypt (phone: 00201143043638; fax: 1770; email: ashraf_20022003@yahoo.com).

A. I. is with the Steel and Structure Engineering Department, National Building Research Center, Egypt (phone: 00201143043638; fax: 1770; email:ayman.m.ismail@gmail.com). triangular tension leg platform (TLP) shown in Fig.1. is a hybrid structure that, with respect to the horizontal degrees

of freedom, is compliant and behaves like a floating structure, whereas with respect to the vertical degrees of freedom it is stiff and resembles a fixed structure and is not allowed to float freely. The triangular TLP is compliant in horizontal plane, but quite rigid in the vertical direction. The TLP has a six degree of freedom, shown in Fig. 2. Which can be conveniently divided into two categories, those controlled by the stiffness of tethers, and those controlled by the buoyancy. The former category includes motion in the vertical plane and consists of heave, roll and pitch; whereas the latter comprises the horizontal motions of surge, sway and yaw..

Most of the literature available Natvig and Vogel, 1995, focused on design of future TLPs should be on the aspects of the platform geometry that affects tether loading and on the tether system itself. Their experience with a four-legged TLP has shown that the indeterminate tether system implies some very heavy cost items. The new concept of a three-legged TLP, which is statically determinate, will not require complicated devices and the foundations can be placed with larger tolerances without affecting tether behavior. The main aspect of three-legged TLP is that all tethers share approximately the same loads despite weather directions. With the near-equal load sharing of the three-legged TLP, the maximum load level in one group is less, thus requiring less tether cross section material than that of a four-legged TLP. Studies indicate that 12 tethers are feasible for a three-legged TLP whilst 16 would be required for a four-legged equivalent TLP. This is thus an important area for savings since tethers are important cost items. Chandrasekaran and Jain, 2002 investigated the structural response behavior of the triangular TLP under several random sea wave loads and current loads in both time and frequency domains. They studied the effect of coupling of stiffness coefficients in the stiffness matrix and the effect of variable submergence of the structure, due to varying water surface, on the structural response of the triangular TLP. Chandrasekaran et.al, 2007, focuses on the response analysis of triangular tension leg platform (TLP) for different wave approach angles varying from 0 through 90 and its influence on the coupled dynamic response of triangular TLPs. A.M.Abou-Rayan, and Amr R. El-gamal [1] developed a numerical study on determining the dynamic responses of a triangular TLPs subjected to regular wave. They found that 
While coupling has a non significant effect on the surge, the heave, and tether tension force, it has a significant effect on the pitch response (this is due to the fact that the structure is not symmetric) in which ignoring the coupling effect will lead to overestimation of the pitch response. For short wave periods (less than $10 \mathrm{sec}$ ), the system responds in small amplitude oscillations about a displaced position that is inversely proportional to the wave period and directly proportional to wave height. On the other hand, for relatively long wave period (12.5 or $15 \mathrm{sec}$ ), the system tends to respond in high oscillations amplitude about its original position. The aforementioned are true for surge and heave responses. M. A. Gasim, et al., constructs a MATLAB program for determining the dynamic responses of square and triangular TLPs subjected to random waves. The structure has been considered as a rigid body and all the six motions have been determined. Linear Airy wave theory and Morison equation have been used for wave force calculations. Newmark Beta Method of time domain analysis has been used for the dynamic analysis. The response amplitude operators (RAO) for typical square and triangular TLPs have been compared with available theoretical results. The results have proved the capability of the developed program in predicting the responses and have indicated that except for surge, the responses of triangular TLP are much higher than that of square TLP.

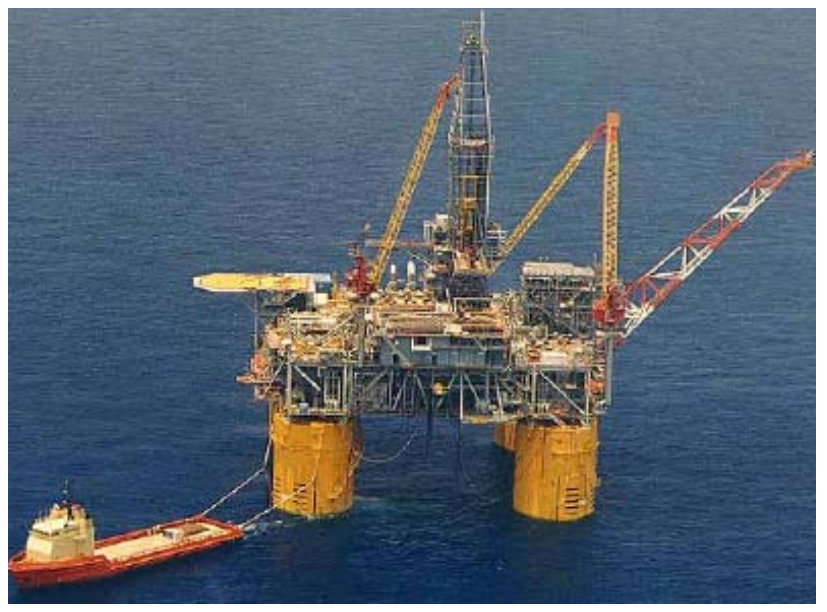

Fig.1. Mars TLP (Gulf of Mexico) (http://www.offshore-technology. com/ projects/mars/images/mars1. mars1.jpg)

In this paper, a numerical study was conducted to investigate the dynamic response of a triangular TLP (shown in Fig. 2) under hydrodynamic forces considering all degrees of freedom of the system. The analysis was carried out using modified Morison equation in the time domain with water particle kinematics using Airy's linear wave theory to investigate the effect of changing the tether tension force on the stiffness matrix of TLP's, the dynamic behavior of TLP's; and on the fatigue stresses in the cables. The effect was investigated for different parameters of the hydrodynamic forces such as wave periods, and wave heights. The numerical study takes into consideration the effect of coupling between various degrees of freedom. The stiffness of the TLP was derived from a combination of hydrostatic restoring forces and restoring forces due to cables and the nonlinear equations of motion were solved utilizing Newmark's beta integration scheme. The effect of wave characteristics such as wave period and wave height on the response of TLP's was evaluated. Only uni-directional waves in the surge direction was considered in the analysis.

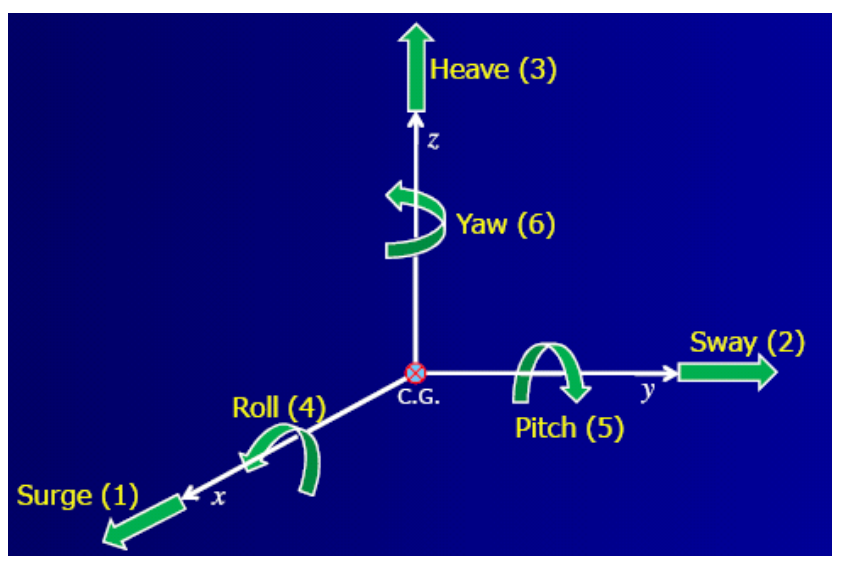

Fig.2. Six degree of freedom of offshore structure.

\section{STRUCTURAL IDEALIZATION AND ASSUMPTIONS}

The general equation of motion of the triangular configuration TLP model under a regular wave is given as

$$
[M]\left\{x \bullet \bullet+[C]\left\{x^{\bullet}\right\}+[K]\{x\}=\{F(t)\}\right.
$$

where, $\{\mathrm{x}\}$ is the structural displacement vector, $\left\{\mathrm{x}^{*}\right\}$ is the structural velocity vector, $\left\{\mathrm{x}^{*}\right\}$ is the structural acceleration vector; $[\mathrm{M}]$ is the structure mass matrix; $[\mathrm{C}]$ is the structure damping matrix; $[\mathrm{K}]$ is the structure stiffness matrix; and $\{\mathrm{F}$ $(\mathrm{t})\}$ is the hydrodynamic force vector.

The mathematical model derived in this study assumes that the platform and the tethers are treated as a single system and the analysis is carried out for the six degrees of freedom under different environmental loads where wave forces are estimated at the instantaneous equilibrium position of the platform utilizing Morison's equation and using Airy's linear wave theory. Wave force coefficients, $C_{d}$ and $C_{m}$, are the same for the pontoons and the columns and are independent of frequencies as well as constant over the water depth. The following assumptions were made in the analysis.

1) Change in pre-tension is calculated at each time step, so the equation of equilibrium at each time step modifies the elements of the stiffness matrix.

2) The platform has been considered symmetrical along the surge axis. Directionality of wave approach to the structure has been ignored in the analysis and only a unidirectional wave train has been considered.

3) The damping matrix has been assumed to be mass and stiffness proportional. 
4) The force on tethers (gravity, inertia, and drag, hydrostatic and hydrodynamic forces) has been neglected because of its small area and also the tether curvature is not significant in motion; only the axial forces acting on tethers have been considered.

5) Hydrodynamic forces on connecting members and mooring legs have been neglected.

6) The wave, current and structure motions are taken to occur in the same plane and in the same direction, the interaction of wave and current has been ignored.

7) Integration of hydrodynamic inertia and drag forces are carried out up to the actual level of submergence, when variable submergence is considered.

\section{DEVELOPMENT OF A TRIANGULAR TLP MODEL}

\section{A. Draft Evaluation}

At the original equilibrium position, Fig. 3, summation of forces in the vertical direction gives:

$W+T=F_{B}$

We find that

$D_{r}=\left[\left\{\left(W+T_{t}\right) /\left(\frac{3}{4} \rho \pi g\right)-\left(D_{p}^{2} s\right)\right] / D_{c}^{2}\right]$

where, $\mathrm{F}_{\mathrm{B}}$ is the total buoyancy force; $\mathrm{W}$ is the total weight of the platform in air; $\mathrm{T}$ is the total instantaneous tension in the tethers; $T_{o}$ is the initial pre-tension in the tether; $p$ is the mass density of sea water; $D_{c}$ is the diameter of TLP columns; $D_{p}$ is the diameter of pontoon; $S_{a}$ and $S_{b}$ are the length of the pontoon between the inner edges of the columns in the $\mathrm{x}$ and $\mathrm{y}$ directions, respectively; and $\mathrm{D}_{\mathrm{r}}$ is the draft.

We notice from eq. (3) that drift distance directly proportion to tether tension force.

\section{B. Stiffness Matrix of Triangular TLP Configuration}

The stiffness of the platform is derived from a combination of hydrostatic restoring forces and restoring forces due to the cables. Restoring force for motions in the horizontal plane (surge, sway, and yaw) are the horizontal component of the pretension in the cables, while restoring forces for motions in the vertical plane arise primarily from the elastic properties of the cables, with a relatively small contribution due to hydrostatic forces.

For more detailed about the derivation of the stiffness matrix, the reader is referred to [1]

The overall stiffness matrix shows:

1) The presence of off-diagonal terms, which reflects the coupling effect between the various degrees of freedom.

2) The coefficients depend on the change in the tension of the tethers, which is affecting the buoyancy of the system. Hence, the matrix is response dependent.

3) Hence, during the dynamic analysis, the [K] matrix is not constant for all time instants, but its components are continuously changing at each time step depending upon the response values at the previous time step.

4) The coefficient for heave stiffness matrix doesn't depend on tether tension force while the surge coefficient directly proportion to tether tension force and inverse proportion to tether length.
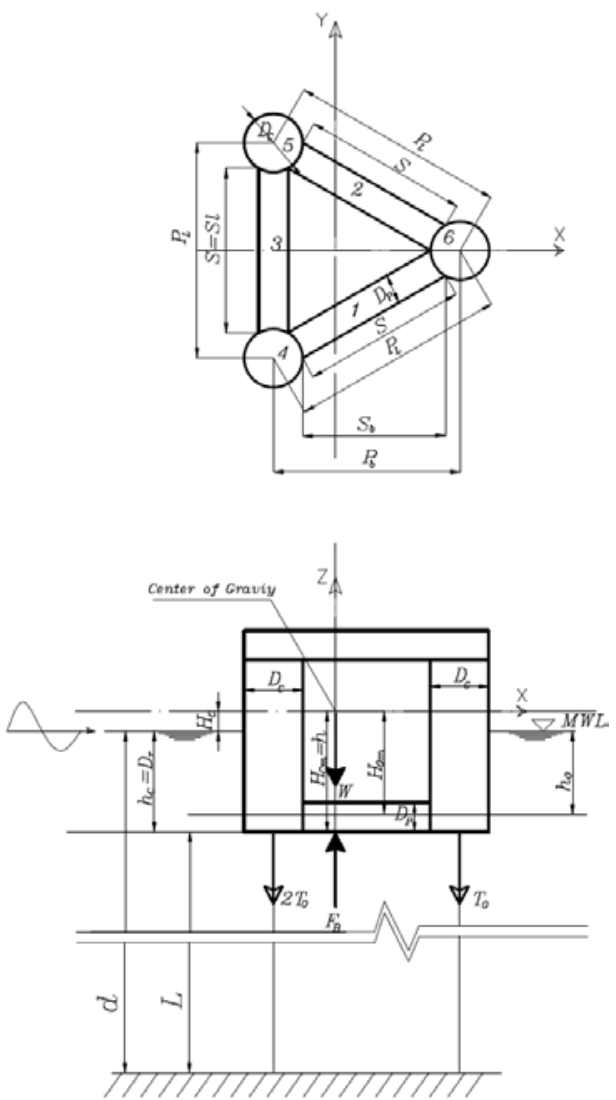

Fig. 3 The Triangular TLP (plan and elevation)

\section{Mass Matrix, [M]}

The mass matrix is assumed to be lumped at each degree of freedom. Hence, it is diagonal in nature and is constant. However, the added mass, Ma, due to the water surrounding the structural members has been considered up to the mean sea level (MSL) and arising from the modified Morison equation. The presence of off diagonal terms in the mass matrix indicates a contribution of the added mass due to the hydrodynamic loading. The fluctuating components of added mass due to the variable submergence of the structure in water is considered in the force vector depending upon whether the sea surface elevation is above or below the MSL. The loading will be attracted only in the surge, heave and pitch degrees of freedom due to the unidirectional wave acting in the surge direction on a symmetric configuration of the platform about the $\mathrm{x}$ and $\mathrm{z}$ axes.

For more detailed about the derivation of the mass matrix, the reader is referred to [1]

D. Structural Damping [C] 
Structure Damping was presented in the form of mass matrix is assumed to be mass and restoring force proportional,.

$$
c=m\left(\sum_{n=1}^{n=6} \frac{2 \zeta_{n} \omega_{n}}{M_{n}} \phi_{n} \phi_{n}{ }^{T}\right) m
$$

Where; $\left\{\varnothing_{n}\right\}$ and $\omega_{n}$ are the mode shapes and structure's natural frequencies, $\zeta_{n}$ is the structural damping ratio, $C$ is the damping matrix, $m$ is the total structure mass matrix and $M_{n}$ is the corresponding element of the $\left\{\varnothing_{n}\right\}^{\mathrm{T}}[m]\left\{\varnothing_{n}\right\}$

This matrix is calculated based on the initial values of $[K]$ and $[M]$ depending on the type of the platform.

\section{E. Hydrodynamic Force Vector, $\{F(t)\}$ on Triangular TLP}

The hydrodynamic force vector is calculated in each degree of freedom according to modified Morison's equation which takes into account the relative velocity and acceleration between the structure and the fluid particles. It is also worth mentioning that the ratio $d / H$ can be related to $d / \lambda$. Based on the limiting heights of breaking waves, it become unstable and break when $H / \lambda \geq 0.1$, ( $H$ is the wave height and $\lambda$ is the wave length).

For the uni-directional wave train in the surge direction, the force vector $\{\mathrm{F}(\mathrm{t})\}$, is given by

$$
F(t)=\left\{\begin{array}{llllll}
F_{11} & F_{21} & F_{31} & F_{41} & F_{51} & F_{61}
\end{array}\right\}^{T}
$$

Since the wave is unidirectional, there would be no force in the sway degree-of-freedom $F_{21}$ and hence there will be no moment in the roll degree of-freedom $\mathrm{F}_{41}$. Because of the vertical water particle velocity and acceleration, the heave degree-of-freedom would experience wave force $F_{31}$. The force in the surge direction $F_{11}$ on the vertical members will cause moment in the pitch degree-of-freedom $\mathrm{F}_{51}$. However, forces in the surge degree-of-freedom are symmetrical about the $\mathrm{X}$ axis (due to the symmetry of the platform to the approaching wave) and there will be no net moment caused in the yaw degree-of-freedom $\mathrm{F}_{61}$.

For more detailed about the derivation of the force vector, the reader is referred to [1]

\section{F. Solution of the Equation of Motion in the Time Domain}

The equation of motion is coupled and nonlinear and can be written as

$$
[M]\left\{x^{\bullet}(t+\Delta t)\right\}+[C]\left\{x^{\bullet}(t+\Delta t)\right\}+[K]\{x(t+\Delta t)\}=\{F(t+\Delta t)\}
$$

Equation (6) is nonlinearly coupled, because of the presence of structural displacement, velocity and acceleration in the right hand side of the equation. Therefore, the force vector should be updated at each time step to account for the change in the tether tension. To achieve this response variation a time domain analysis is carried out. The Newmark's beta time integration procedure is used in a step wise manner. This procedure was developed by Newmark together with a family of time-stepping methods. The following values are updated 1) Stiffness coefficients which vary with tether tension.
2) Added mass which varies with sea surface fluctuations.

3) Wave forces at the instantaneous position of the displaced structure.

\section{RESULTS AND DISCUSSION}

A numerical program was developed using MATLAB software where solution based on Newmark's beta method was obtained. The studied TLP geometrical, physical and the mechanical properties of the tethers are shown in Table I.

The main dynamic charchatrstic of the system chosen in the study are given in table II, Such as natural period of the triangle TLP

It can be note from table II that tow triangle TLP has a high natural period in horizontal plan where as small natural period in vertical direction.

Also, it can be seen that changing the pretension force in tethers has a valuable effect on the natural period of horizontal movement (surge, sway and yaw movement)

While has little effect on the natural period on the movement in the vertical direction that is heave, roll and pitch

It is obvious that the horizontal plan movement the natural period is inversely proportional to the tether tension force this is because increasing the tether tension force increase the TLP stiffness

\begin{tabular}{|c|c|}
\hline \multicolumn{2}{|l|}{ Water properties } \\
\hline Gravity acceleration $\left(\mathrm{m} / \mathrm{sec}^{2}\right)$ & 9.81 \\
\hline Water weight density $\left(\mathrm{kN} / \mathrm{m}^{3}\right)$ & 10 \\
\hline Inertia coefficient, $\mathrm{C}_{\mathrm{m}}$ & 1.7 \\
\hline Drag oefficient, $C_{d}$ & 0.8 \\
\hline Current velocity (m/sec), $\mathrm{U}_{\mathrm{c}}$ & 0 \\
\hline Wave period (sec), $\mathrm{T}_{\mathrm{w}}$ & 10 and 15 \\
\hline Wave height $(\mathrm{m}), \mathrm{H}_{\mathrm{w}}$ & 8 and 10 \\
\hline \multicolumn{2}{|l|}{ Platform properties } \\
\hline Platform weight (KN),W & 330000 \\
\hline Platform length (m), $\mathrm{P}_{1}$ & 75.66 \\
\hline Platform radius of gyration in $\mathrm{x}$-directions $(\mathrm{m}), \mathrm{r}_{\mathrm{x}}$ & 35.1 \\
\hline Platform radius of gyration in y-directions $(\mathrm{m}), \mathrm{r}_{\mathrm{y}}$ & 35.1 \\
\hline Platform radius of gyration in $\mathrm{z}$-directions $(\mathrm{m}), \mathrm{r}_{\mathrm{z}}$ & 42.4 \\
\hline Tether total force (KN),T & $\begin{array}{l}67750,101625 \text { and } \\
135500\end{array}$ \\
\hline Tether area $\left(\mathrm{m}^{2}\right)$ & 0.40 \\
\hline Draft (m) & $19.3,24.8$ and 30.3 \\
\hline Tether modulus of elasticity $\left(\mathrm{kn} / \mathrm{m}^{2}\right), \mathrm{E}$ & $2.2 \mathrm{e} 7$ \\
\hline Diameter of columns $(\mathrm{m}), \mathrm{D}_{\mathrm{c}}$ & 16.17 \\
\hline Diameter of pontoon (m), $\mathrm{D}_{\mathrm{P}}$ & 13.86 \\
\hline Center of gravity above the keel (m), h & 27.47 \\
\hline Water depth (m),d & 1000 \\
\hline Damping ratio, $\zeta$ & 0.05 \\
\hline
\end{tabular}

TABLE I

GEOMETRIC PROPERTIES OF THE SQUARE TLP AND LOAD DATA

TABLE II

CALCUlated Natural Structural PeRiods For DifFerent ANALysis CASES (IN SECONDS)

\begin{tabular}{cccc}
\hline \hline \multirow{3}{*}{ DOF } & \multicolumn{3}{c}{ Analysis Case } \\
\cline { 2 - 4 } & Tether total & Tether total & Tether total \\
& force & force & force \\
\hline
\end{tabular}




\begin{tabular}{cccc}
\cline { 2 - 4 } & $67750 \mathrm{KN}$ & $101625 \mathrm{KN}$ & $135500 \mathrm{KN}$ \\
\hline Surge & 172.7126 & 143.8854 & 126.9949 \\
Sway & 172.7126 & 143.8854 & 126.9949 \\
Heave & 2.7535 & 2.746 & 2.7384 \\
Roll & 2.7834 & 2.7666 & 2.7533 \\
Pitch & 2.7834 & 2.7666 & 2.7533 \\
Yaw & 114.666 & 94.8281 & 83.9491 \\
\hline \hline
\end{tabular}

A. Surge Response

The time histories of the surge responses for the triangular TLP are shown in Figs. 4 to 7. It is observed that, for a specific wave period, the amplitude of oscillations increases as the wave height increases. For short period the system responds in small amplitude oscillations about a displaced position that is dependent to wave height and pretension force in tether. The amplitude of oscillations increases with the increase in the wave period, which is expected because as the wave period increases, it becomes closer to the surge natural period of vibration (about 150 sec.). Moreover, in all cases, the surge response seems to have periodic oscillations that have the same exciting wave period [3].

The effect of tether tension force is obvious in Figs. 4 to 7 which indicate that it affect the drift value of the displaced position. As tension force becomes bigger the drift decreases but the force of the tethers has little effect on the amplitude of the oscillation. Finally, the transient state takes about 100-200 seconds where the stationary state begins.

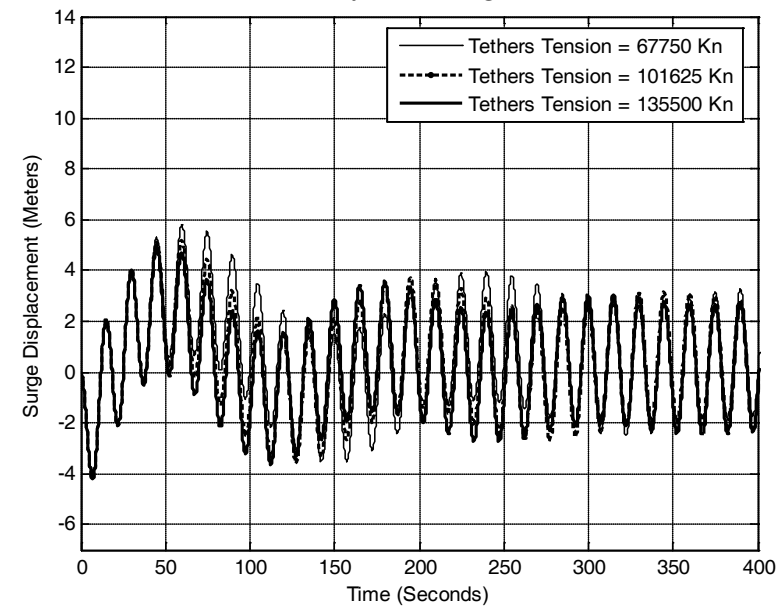

Fig. 4 Coupled Surge response of triangular TLP for Wave Height $=8 \mathrm{~m}$ and wave period $=15 \mathrm{sec}$

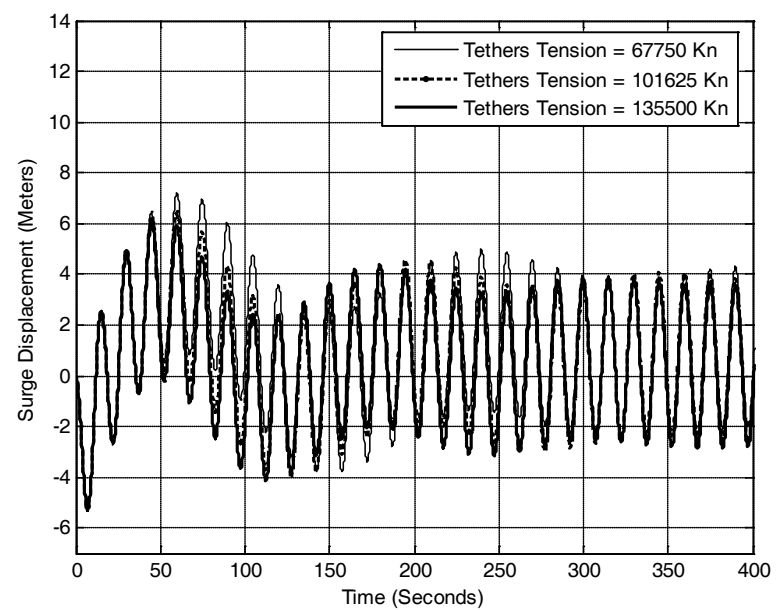

Fig. 5 Coupled Surge response of triangular TLP for Wave Height $=10 \mathrm{~m}$ and wave period $=15 \mathrm{sec}$.

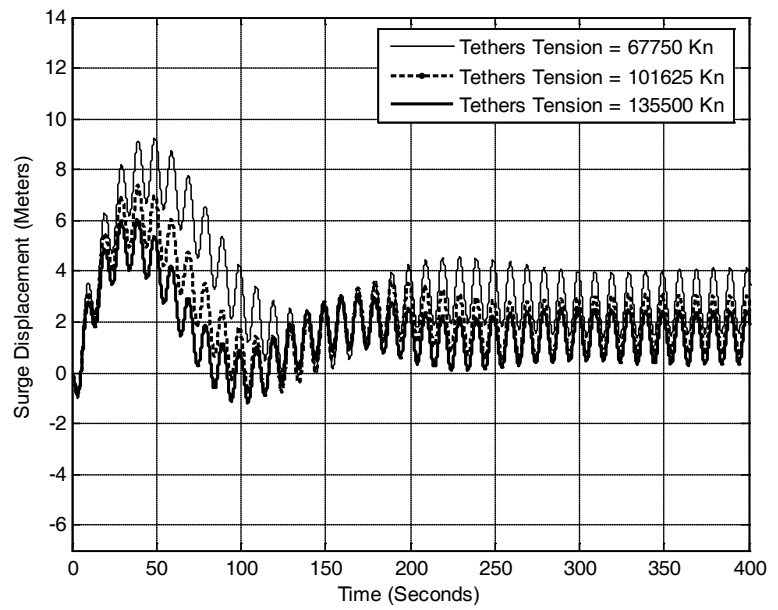

Fig. 6 Coupled Surge response of triangular TLP for Wave Height $=8 \mathrm{~m}$ and wave period $=10 \mathrm{sec}$.

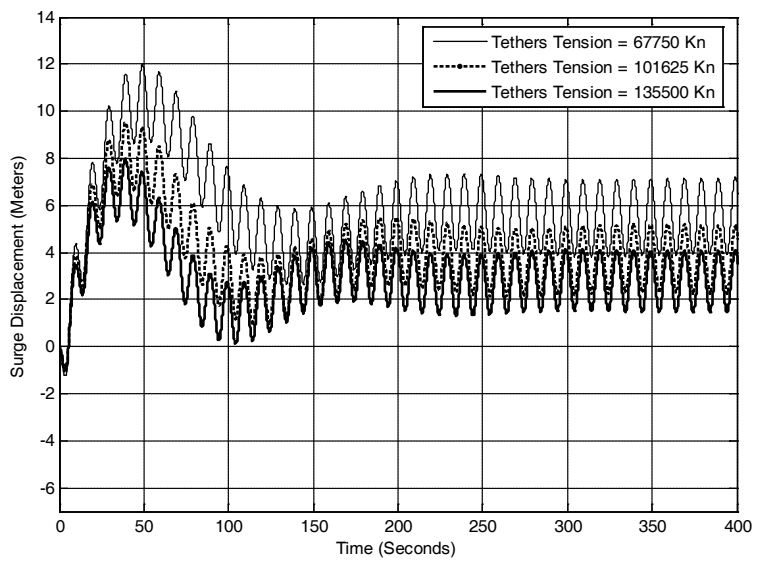

Fig. 7 Coupled Surge response of triangular TLP for Wave Height $=10 \mathrm{~m}$ and wave period $=10 \mathrm{sec}$.

\section{B. Heave Response}

The time histories are shown in Figs. 8 to 11. As expected, the response in the heave direction has very small values compared to that of the surge direction. This is attributed to 
the relatively high stiffness of the tethers in this direction together with the fact that the excitation is indirect in this case. Moreover, the heave response is inversely proportional to the wave period and directly proportional to wave height. The heave response appears to have a mean value of nearly zero. It is obvious that the increase of tether tension decrease slightly the amplitude of the heave response. Also, the transient state takes about 10 seconds where the stationary state begins and the motion is almost periodic.

It is interesting to note that, even both: the stiffness of TLP and the hydrodynamic force doesn't depend directly on tether tension force in heave movement, the increase in tether tension force leads to increase in the drift value which reduce the tether length, which affect indirectly the heave movement. Even the exciting hydraulic force is periodical sin wave the heave movement has more peaks value, illustrating higher mode contribution in the response.

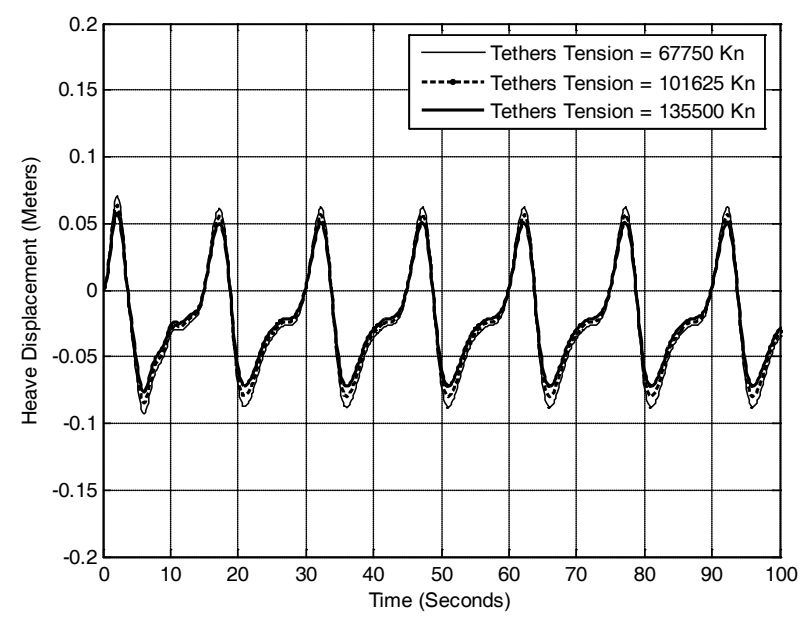

Fig. 8 Coupled Heave response of triangular TLP for Wave Height $=8 \mathrm{~m}$ and wave period $=15 \mathrm{sec}$.

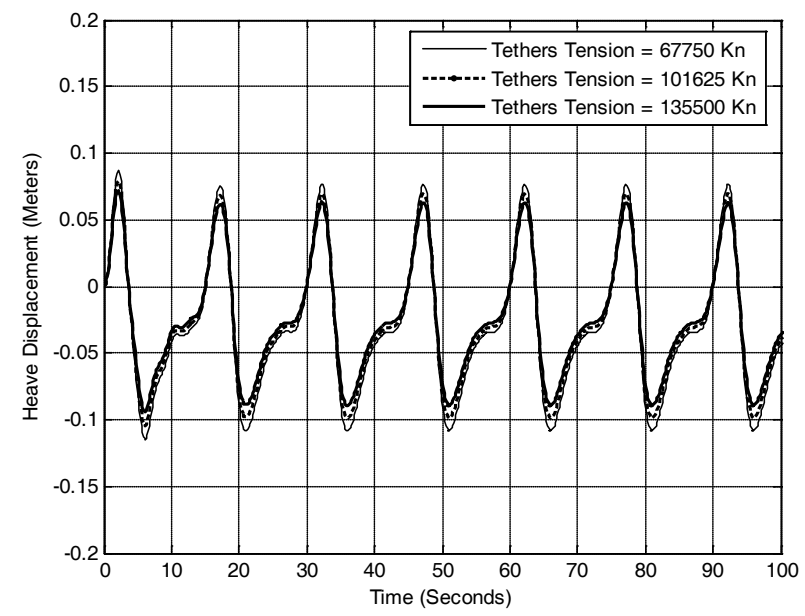

Fig. 9 Coupled Heave response of triangular TLP for Wave Height $=10 \mathrm{~m}$ and wave period $=15 \mathrm{sec}$

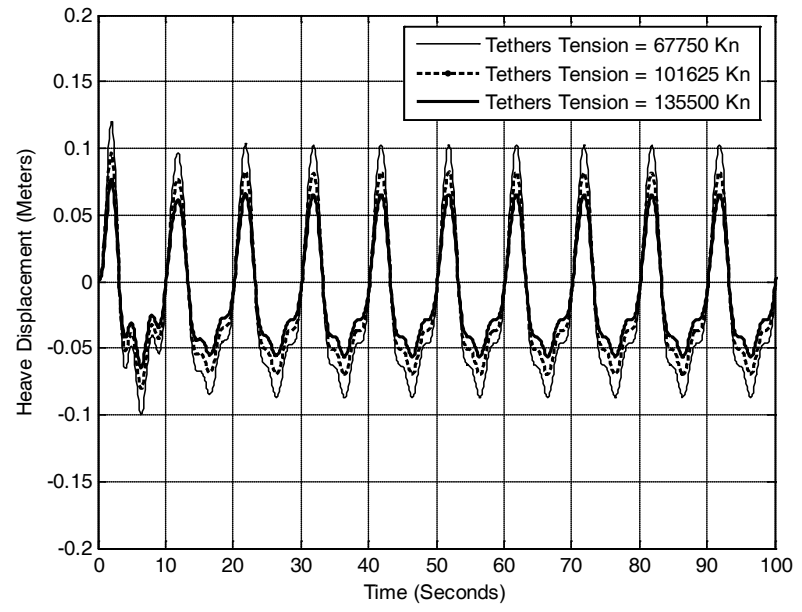

Fig. 10 Coupled Heave response of triangular TLP for Wave Height $=8 \mathrm{~m}$ and wave period $=10 \mathrm{sec}$

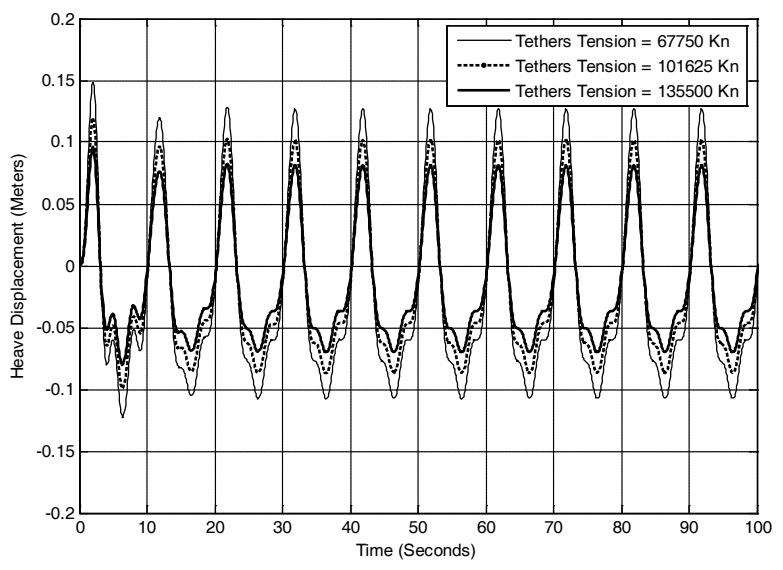

Fig. 11 Coupled Heave response of triangular TLP for Wave Height $=10 \mathrm{~m}$ and wave period $=10 \mathrm{sec}$

\section{Pitch Response}

The time histories shown in Figs. 12 to 15 it is clear that the increase of tether tension decrease the amplitude of the pitch response and that effect is more obvious for small wave period. Also the pitch response is inversely proportional to the wave period and directly proportional- but to a less extent- to wave height. The pitch response appears to have a mean value of nearly zero. Moreover, the transient state takes about 20-40 seconds before the stationary state begins. 


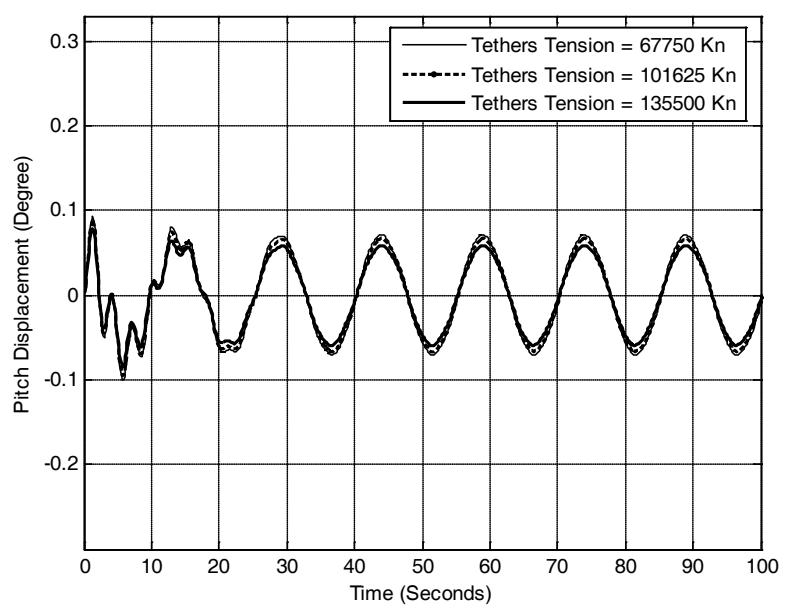

Fig. 12 Coupled Pitch response of triangular TLP for Wave Height $=8 \mathrm{~m}$ and wave period $=15 \mathrm{sec}$

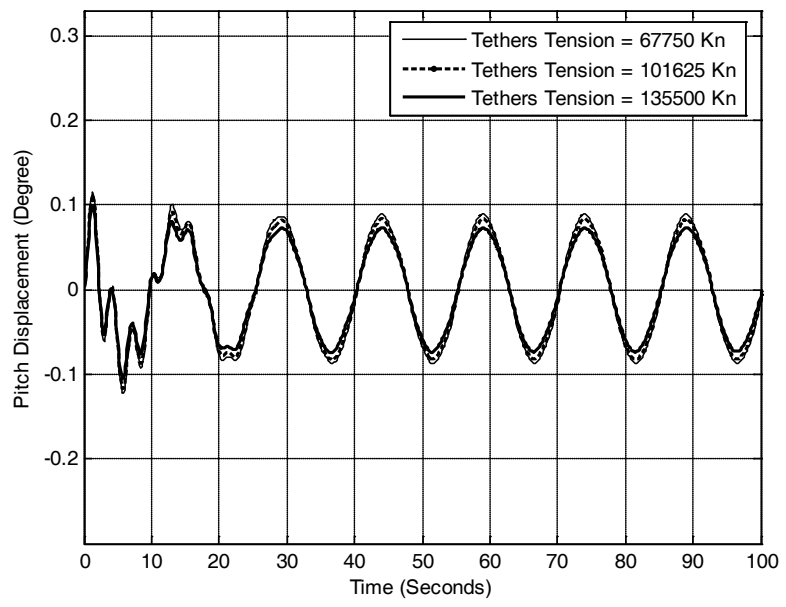

Fig. 13 Coupled Pitch response of triangular TLP for Wave Height $=10 \mathrm{~m}$ and wave period $=15 \mathrm{sec}$

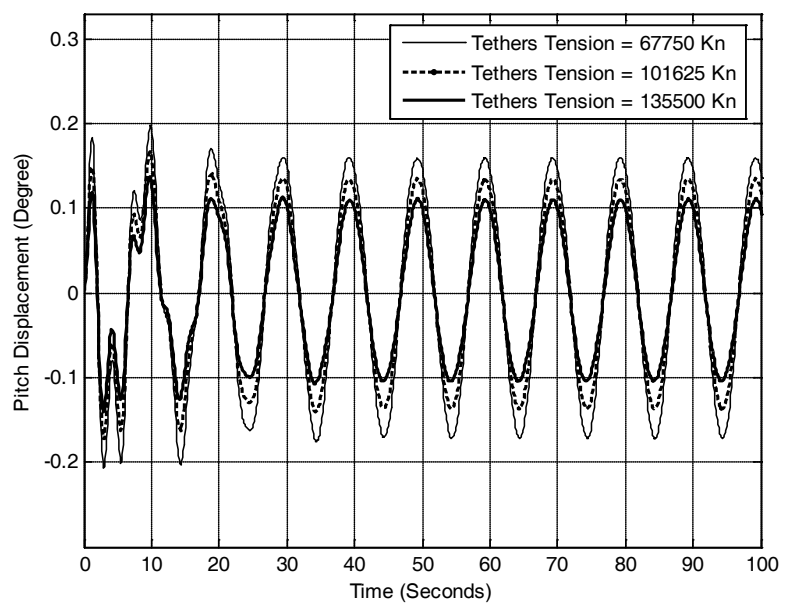

Fig. 14 Coupled Pitch response of triangular TLP for Wave Height $=8 \mathrm{~m}$ and wave period $=10 \mathrm{sec}$

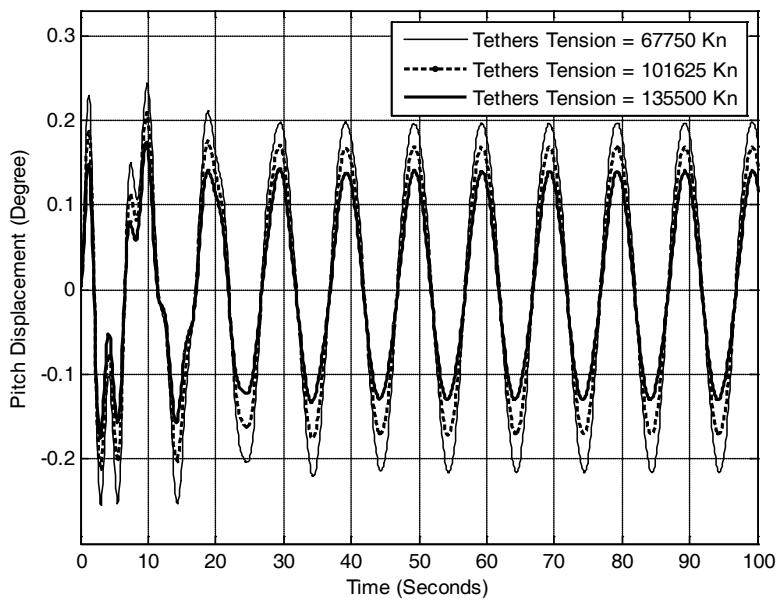

Fig. 15 Coupled Pitch response of triangular TLP for Wave Height $=10 \mathrm{~m}$ and wave period $=10 \mathrm{sec}$

\section{Change in tether tension force}

The time histories for the change in tether tension force for the square TLP are shown in Figs. 16 to 19.

It is noted that for small value of tether pretension the change in it is force is approximately $36 \%$ of it is initial force which may lead to fatigue failure, for big pretension force the ratio of change in force to it is initial value is about $10 \%$ so for same stress levels as pretension force reduced the probability of fatigue occurrence will increases.

For long wave period the change of tether tension force is not affected by the initial tether tension force as the magnitude of the tension change is slightly different.

For short wave period it can be observed that the permanent increase in tether tension force is higher for smaller initial tether tension force.

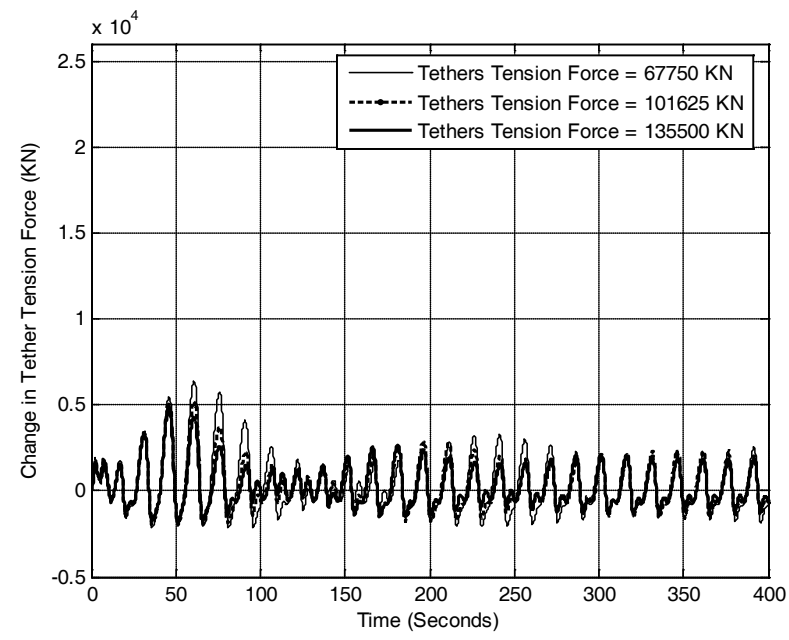

Fig. 16 Change in tether tension force of triangular TLP for Wave Height $=8 \mathrm{~m}$ and wave period $=15 \mathrm{sec}$ 


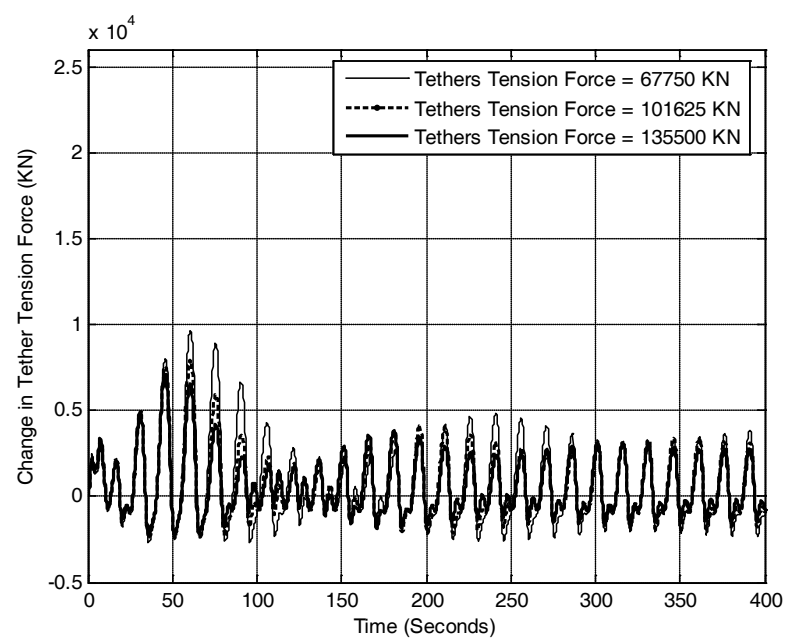

Fig. 17 Change in tether tension force of triangular TLP for Wave Height $=10 \mathrm{~m}$ and wave period $=15 \mathrm{sec}$

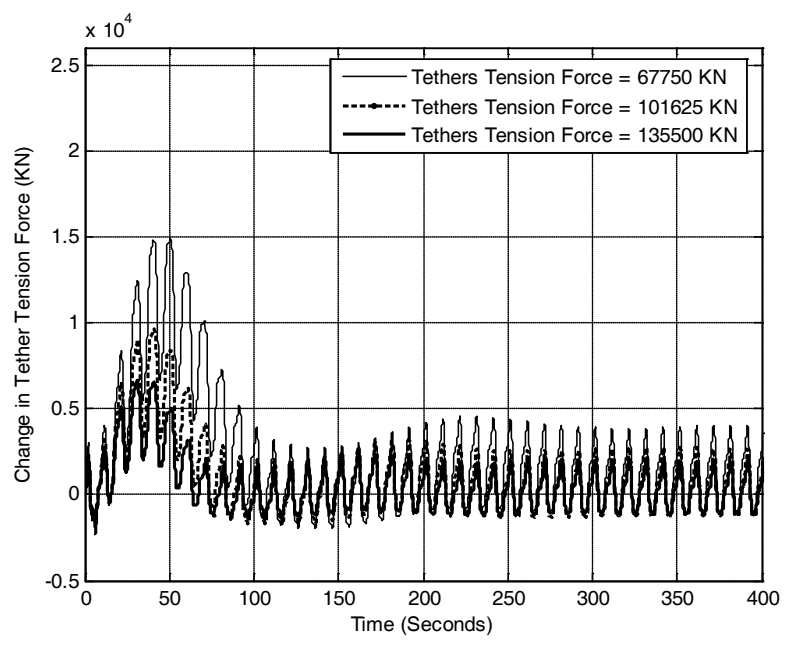

Fig. 18 Change in tether tension force of triangular TLP for Wave Height $=8 \mathrm{~m}$ and wave period $=10 \mathrm{sec}$

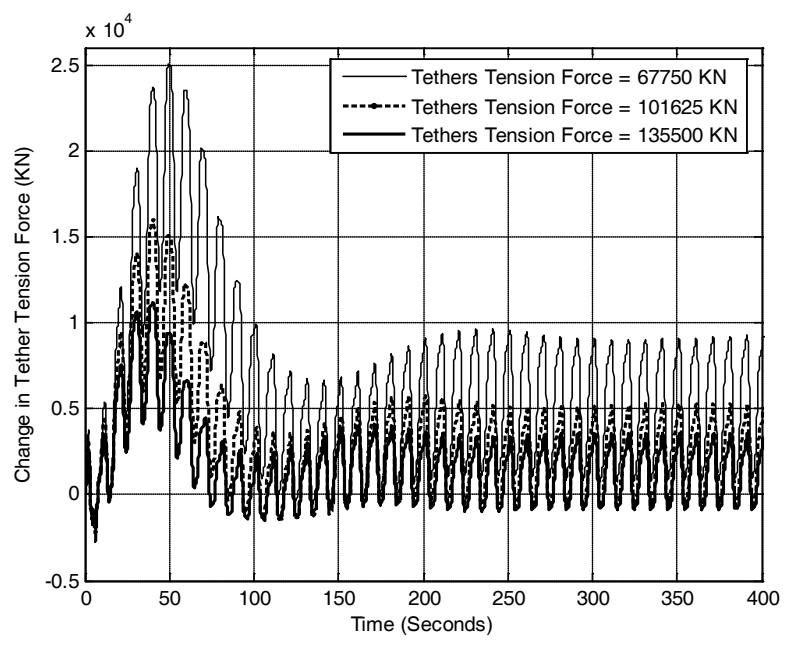

Fig. 19 Change in tether tension force of triangular TLP for Wave Height $=10 \mathrm{~m}$ and wave period $=10 \mathrm{sec}$

\section{CONCLUSIONS}

In this study a computer program was used to study the dynamics properties of triangle TLP, with concentration on the effect of tether pretension force the main conclusions were

1. The tether tension force value effect the natural period for horizontal movement of triangle TLP while has little effect for vertical movements.

2. The tether tension force value effect the amplitude of surge movement where, its effect on the amplitude of heave and pitch movements is less noticed.

3. The transition time for triangle to reach a stable condition may reach up to 250 second.

4. For same stress level in tethers the change in tether tension force leading to probability of fatigue failure is more pronounced in short move periods and in small value of tether per tension force.

\section{REFERENCES}

[1] Abou-Rayan, A.M., Seleemah, A., and El-gamal, A.R., " Wave induced motion of a triangular tension leg platforms in deep waters ", Ocean Systems Engineering, Vol. 3 (2), 2013, pp. 149 - 165.

[2] Chandrasekaran, S., Jain, A. K., "Triangular configuration tension leg platform behavior under random sea wave loads", Ocean Engineering, 29(15):1895-1928. [doi:10.1016/S0029-8018(01)00111-1], 2002b.

[3] Chandrasekaran, S., A. K. Jain, A. Gupta, A. Srivastava,"Response behaviour of triangular tension leg platforms under impact loading", Ocean Engineering 34 (2007) 45-53.

[4] Natvig, B. J., Vogel, H., 1995," TLP design philosophy—past, present, future", In: Proceedings of ISOPE, The Hague, pp. 64-69.

[5] Gasim, M. A., Kurian, V. J., Narayanan, S. P., Kalaikumar, V., "Responses of Square and Triangular TLPs Subjected to Random Waves", In: proceeding of ICCBT, Malaysia, 2008, pp. 133-140. 